\title{
Reduced shrinkage stress via photo-initiated copper(I)-catalyzed cycloaddition polymerizations of azide-alkyne resins
}

\author{
AUTHORS: Han Byul Song ${ }^{1}$, Nancy Sowan ${ }^{2}$, Parag K. Shah ${ }^{1}$, Austin Baranek ${ }^{1}$, Alexander Flores ${ }^{1}$, \\ Jeffrey W. Stansbury ${ }^{1,3}$, and Christopher N. Bowman ${ }^{* 1,2}$ \\ ${ }^{1}$ Department of Chemical and Biological Engineering, University of Colorado Boulder, 596 UCB, Boulder, CO, United \\ States.
}

${ }^{2}$ Materials Science and Engineering Program, University of Colorado Boulder, 596 UCB, Boulder, CO, United States.

${ }^{3}$ Department of Craniofacial Biology, School of Dental Medicine, Anschutz Medical Campus, Aurora, CO, United States.

KEY WORD: Photopolymerization; CuAAC; stress; shrinkage; modulus; flexural strength; dental resins; click chemistry; step-growth polymerization.

\begin{abstract}
Objectives. Polymerization shrinkage stress and factors involved in the stress development such as volumetric shrinkage and modulus were investigated in photo-CuAAC (photoinitiated copper(I)-catalyzed azide-alkyne cycloaddition) polymerization and compared with conventional BisGMA-based methacrylate polymerization for their use as alternative dental resins. Methods. Tri-functional alkyne and di-functional azide monomers were synthesized for photo-CuAAC polymerization. Conversion kinetics, stress development and polymerization shrinkage were determined with FTIR spectroscopy, tensometery, and with a linometer, respectively, for CuAAC and BisGMAbased monomer mixtures using a camphorquinone/amine visible light photoinitiator system. Thermomechanical properties for the cured polymer matrices were characterized by dynamic mechanical analysis and in three-point bending on a universal testing machine. Polymerization kinetics, polymerization shrinkage stress, dynamic volumetric shrinkage, glass transition temperature $\left(\mathrm{T}_{\mathrm{g}}\right)$,


flexural modulus, flexural strength, and flexural toughness were compared between the two different resin systems. Results. A glassy CuAAC polymer $\left(\mathrm{T}_{\mathrm{g}}=62^{\circ} \mathrm{C}\right)$ exhibited $15-25 \%$ lower flexural modulus of $2.5 \pm 0.2 \mathrm{GPa}$ and flexural strength of $117 \pm 8 \mathrm{MPa}$ compared to BisGMA-based polymer $\left(\mathrm{T}_{\mathrm{g}}=160{ }^{\circ} \mathrm{C}\right)$ but showed considerably higher energy absorption around 7.1 $\mathrm{MJ} \times \mathrm{m}^{-3}$ without fracture when strained to $11 \%$ via three-point bend compared to the flexural toughness of $2.7 \mathrm{MJ} \times \mathrm{m}^{-3}$ obtained from BisGMAbased polymer. In contrast to BisGMA-based polymers at $75 \%$ functional group conversion, the CuAAC polymerization developed approximately three times lower shrinkage stress with the potential to achieve quantitative conversion under ambient temperature photocuring conditions. Moreover, relatively equivalent dynamic volumetric shrinkage of around 6-7 \% was observed via both CuAAC and dimethacrylate polymerization, suggesting that the low shrinkage stress of CuAAC polymerization was due to delayed gelation along with slower rate of polymerization and the formation of a more compliant network structure. Significance. CuAAC crosslinked networks possessed high toughness and low polymerization shrinkage stress with quantitative conversion, which eliminated obstacles associated with BisGMA-based dental resins including limited conversion, unreacted extractable moieties, brittle failure, and high shrinkage stress.

\section{INTRODUCTION}

Dimethacrylate monomers like BisGMA (bisphenol A glycidyl methacrylate) have been widely utilized in practical dental restorative material applications such as dental composites for decades due to rapid polymerization kinetics, high mechanical performance, and desirable aesthetic properties [1]. However, the final conversion of methacrylate-based free radical photopolymerization is often limited by the onset of vitrification, which is dictated by the chain growth polymerization and resin composition that governs the overall mechanical behavior. Therefore, the restricted maximum conversion regardless of enhanced mechanical properties leads to a potential for monomer leaching due to the presence of extractable monomers in the resin matrices, which raises concerns of toxicity in addition to declining 
mechanical performance. In addition, methacrylate-based polymers develop considerable shrinkage stress during the polymerization that is governed by post-gelation volumetric contraction and elastic modulus evolved primarily during vitrification in a restricted environment [2,3]. As previously reported, the polymerization shrinkage stress of BisGMA-based resins/composites is controlled by the chemical composition [4-6], rate of polymerization [7,8], degree of conversion [9], and C-factor (configuration factor as a ratio of the bonded surface area to the un-bonded surface area) [10,11]. Significant shrinkage stress can lead to marginal leakage, failure of the restorative, adhesive failure between composite and tooth, staining and secondary caries [11], which are considered to be the main reasons for shortening the lifetime and ultimately necessitating replacement of the dental restorative. Finally, dimethacrylate-based polymers are subject to brittle failure under stress [12] in spite of significant flexural strength, opening the door for more durable alternative dental materials.

Several approaches to minimize polymerization shrinkage stress of dental restoratives, generally dealing with reduction in volumetric shrinkage or incorporating a stress relaxation mechanism, have previously been suggested. Predominantly, increased filler loading in a polymeric matrix reduced volumetric shrinkage and shrinkage stress while significantly improving the overall elastic modulus of a composite material $[13,14]$. Non-functional silanated microfillers have been shown to lower contraction stress at equivalent conversion as opposed to functional silane-treated microfillers since the non-bonded surface of particles enables more free volume and less mechanical adhesion at the interface [15]. One drawback of increasing filler content was light attenuation, which hinders the rate of polymerization and, therefore, lowers the maximum conversion. Alternatively, oligomerization as a means of partially pre-reacting functionalities was used to reduce the concentration of reactive species. For instance, reactive nanogel prepolymer additives generated low shrinkage and stress without significantly affecting light attenuation and polymerization kinetics [16-18]. From the clinical standpoint, curing protocols also influence shrinkage stress development. The incremental layering technique is suggested to 
decrease the C-factor [19], and soft-start or pulse-delay curing techniques were purported to enable stress relaxation through early-stage viscous flow by reducing the initial rate of polymerization using low light intensity [20]. Furthermore, studies focusing on modification of BisGMA-based monomer formulations as well as other alternative chemistries/mechanisms have also highlighted the reduction of volumetric shrinkage and internal stress. Incorporation of pendant bulky groups [21] or urethane derivatives [22] in BisGMA-based monomers generated low shrinkage and stress with improved mechanical properties. Resin formulation with marginally compatible comonomers or with nonreactive linear prepolymer additives yielded reduced shrinkage stress with high conversion by polymerizationinduced phase separation (PIPS) [23,24]. The utilization of thiol-ene and thiol-yne chemistries showed reduction in shrinkage stress via delayed gelation in a step-growth polymerization [25-29], and ringopening polymerization presented low shrinkage due to compensating volume expansion of epoxy or cyclopropane functionalities in both resins and nano-composites [30-32]. Additionally, insertion of allyl sulfide moieties in monomer backbones promoted the bond rearrangement of the network without altering crosslink density via reversible addition fragmentation chain transfer (RAFT) and achieved the relaxation of shrinkage stress [33-35].

In this work, we introduce a photo-initiated copper(I)-catalyzed azide-alkyne cycloaddition (photo-CuAAC) polymerization using a common free radical generating photoinitiator (Scheme 1) as an alternative to the conventional dimethacrylate-based chain growth polymerization due to the following potential benefits: 1. Copper(I)'s longer catalytic lifetime enables greater degrees of polymerization and dark reaction. 2. The step-growth nature of the $\mathrm{CuAAC}$ polymerization leads to a homogenous network with a narrow glass transition. 3. Delayed gelation in step-growth polymerizations reduces shrinkage stress. 4. A triazole-containing polymer network facilitates mechanical enhancement at high conversion. Introduced in 2001 [36,37] and now the most prominent "click" chemistry as it is highly efficient, robust, and orthogonal [38,39], the CuAAC reaction has led to a significant innovation in polymer, 
block copolymer, and dendrimer synthesis [40-43], bioconjugation [44-46], and surface functionalization [47-49]. In 2011, spatio-temporal control of the CuAAC reaction/polymerization via photo-reduction of copper(II) upon light irradiation [50-52] enabled the formation of thermosets consisting of thermally and chemically stable 1,2,3-triazoles and tunable backbones for practical applications [53-59]. New designs of monomers taking into consideration the safety concerns of azide moieties and kinetic and/or mechanical property investigation of bulk photo-CuAAC branched polymers have been performed by several researchers [59-61], highlighting the merits associated with photoCuAAC polymerization including mechanical enhancement from rigid triazole crosslinkers. As previously reported, delayed gelation in a step-growth polymerization allowed internal stress to relax by viscous flow prior to gelation [2] and produced more homogeneous networks with reduced polymerization shrinkage stress. Therefore, we hypothesized that photo-CuAAC polymerization enables the development of a glassy thermoset with enhanced mechanical properties due to triazole formation and low polymerization shrinkage stress via delayed gelation from an initially low viscous resin as an alternative dental resin/composite.

\section{[Scheme 1]}

In the present work, we investigate in situ polymerization kinetics and the development of polymerization shrinkage stress with respect to functional group conversion for both CuAAC polymerizations and a control consisting of a conventional dimethacrylate polymerization. Furthermore, volumetric shrinkage, glass transition, and flexural modulus of the CuAAC polymers were determined in comparison with BisGMA-based polymers as a means to determine primary factors associated with polymerization shrinkage stress.

\section{EXPERIMENTAL SECTION}

1. Materials 
1,3-Bis(2-isocyanatopropan-2-yl)benzene, dibutyltin dilaurate, tetrahydrofuran, 6-chloro-1-hexanol, sodium azide, 1,1,1-tris(hydroxymethyl)propane, propargyl bromide, propargyl alcohol, bisphenol A diglycidyl ether, ethanol, 3-(triethoxysilyl)propyl isocyanate, copper(II) chloride, N,N, $\mathrm{N}^{\prime}, \mathrm{N}^{\prime}, \mathrm{N}^{\prime \prime}$ pentamethyldiethylenetriamine (PMDETA), camphorquinone (CQ), ethyl 4-(dimethylamino)benzoate (EDAB), and acetonitrile were used as received from Sigma Aldrich. Sodium hydroxide, ammonium chloride, dimethyl sulfoxide, dimethylformamide, methanol, and sodium sulfate were used as received from Fisher Scientific. BisGMA/TEGDMA (70/30) comonomers solution was used as received from ESSTECH. Fusion silane coupling agent was used as received from George Taub Products \& Fusion Co., Inc. Bis(6-azidohexyl) (1,3-phenylenebis(propane-2,2-diyl))dicarbamate (BZ-AZ) and 1-(prop-2yn-1-yloxy)-2,2-bis((prop-2-yn-1-yloxy)methyl)butane (AK) were synthesized according to a previously reported procedure [60]. All azides were synthesized according to the azide safety rules and handled with appropriate precaution when working with monomers, resins, and polymers in small quantities [62].

[Figure 1]

Synthesis of bis(6-chlorohexyl) (1,3-phenylenebis(propane-2,2-diyl))dicarbamate intermediate: A solution of 1,3-bis(2-isocyanatopropan-2-yl)benzene $(4.09 \mathrm{mmol})$ and dibutyltin dilaurate (5 drops) in THF $(3 \mathrm{~mL})$ was added in a round bottom flask and purged under nitrogen. The reaction mixture was cooled to $0^{\circ} \mathrm{C}$ in an ice bath, followed by dropwise addition of 6-chloro-1-hexanol $(8.60 \mathrm{mmol}, 1.17 \mathrm{~g})$. The ice bath was removed and the reaction mixture allowed to stir at room temperature for $12 \mathrm{~h}$. The reaction mixture was then passed through a silica plug with excess THF. The product was dried in vacuo as a colorless oil. (98\% yield) ${ }^{1} \mathrm{H}$ NMR $\left(\mathrm{CDCl}_{3}\right)$, ppm: $\delta 1.15-1.85\left(28 \mathrm{H}, \mathrm{m}, \mathrm{CH}_{2}, \mathrm{CH}_{3}\right), 3.52(4 \mathrm{H}, \mathrm{t}$, $\left.\mathrm{CH}_{2}-\mathrm{Cl}\right), 3.97\left(4 \mathrm{H}, \mathrm{t}, \mathrm{CH}_{2}\right.$-carbamate), $5.07(2 \mathrm{H}, \mathrm{s}, \mathrm{NH}$, carbamate), 7.27 (3H, s, CH-aromatic), 7.42 (1H, s, CH-aromatic); ${ }^{13} \mathrm{C}$ NMR $\left(\mathrm{CDCl}_{3}\right), \mathrm{ppm}: \delta 26.3,26.6,29.0,29.4,32.5,45.0,55.4,64.3,121.3$, $123.3,128.4,147.2,154.9$ 
Synthesis of bis(6-azidohexyl) (1,3-phenylenebis(propane-2,2-diyl))dicarbamate (BZ-AZ): A solution

of dicarbamate intermediate $(4.15 \mathrm{mmol})$ and sodium azide $(16.6 \mathrm{mmol}, 1.08 \mathrm{~g})$ in DMF $(30 \mathrm{ml})$ was added to a round bottom flask connected with a reflux condenser. The reaction mixture was stirred at $80^{\circ} \mathrm{C}$ for $12 \mathrm{~h}$. The product was extracted with ethyl acetate and water, dried with $\mathrm{Na}_{2} \mathrm{SO}_{4}$, purified by column chromatography using a hexane:ethyl acetate mixture as eluent, and dried in vacuo as a colorless oil. (93\% yield) ${ }^{1} \mathrm{H}$ NMR $\left(\mathrm{CDCl}_{3}\right)$, ppm: $\delta 1.15-1.75\left(28 \mathrm{H}, \mathrm{m}, \mathrm{CH}_{2}, \mathrm{CH}_{3}\right), 3.25\left(4 \mathrm{H}, \mathrm{t}, \mathrm{CH}_{2}-\right.$ $\mathrm{N}_{3}$ ), 3.97 (4H, t, $\mathrm{CH}_{2}$-carbamate), 5.07 (2H, s, NH, carbamate), 7.27 (3H, s, CH-aromatic), 7.42 (1H, s, $\mathrm{CH}$-aromatic); ${ }^{13} \mathrm{C} \mathrm{NMR}\left(\mathrm{CDCl}_{3}\right), \mathrm{ppm}: \delta 25.5,26.4,29.0,29.3,28.8,51.4,55.4,64.2,121.3,123.3$, $128.4,147.2,154.9$

Synthesis of 3,3'-((propane-2,2-diylbis(4,1-phenylene))bis(oxy))bis(1-azidopropan-2-ol) (BPA-AZ): A solution of bisphenol A diglycidyl ether (12.4 mmol, $4.21 \mathrm{~g}), \mathrm{NH}_{4} \mathrm{Cl}$ (37.1 mmol, $2 \mathrm{~g}$ ), and sodium azide (49.5 mmol, $3.22 \mathrm{~g}$ ) in $\mathrm{H}_{2} \mathrm{O}: \mathrm{EtOH}(25: 100 \mathrm{ml})$ was added to a round bottom flask connected with a reflux condenser. The reaction mixtures were stirred at room temperature for $2 \mathrm{~h}$ and heated to $100^{\circ} \mathrm{C}$ for 12h. The product was extracted with ethyl acetate and water, dried with $\mathrm{Na}_{2} \mathrm{SO}_{4}$, purified by column chromatography using a hexane:ethyl acetate mixture as eluent, and dried in vacuo as a colorless oil. (70 $\%$ yield $){ }^{1} \mathrm{H}$ NMR $\left(\mathrm{CDCl}_{3}\right), \mathrm{ppm}: \delta 1.66\left(6 \mathrm{H}, \mathrm{s}, \mathrm{CH}_{3}\right), 2.55(2 \mathrm{H}, \mathrm{s}, \mathrm{OH}), 3.55,3.78\left(4 \mathrm{H}, \mathrm{m}, \mathrm{CH}_{2}\right), 4.02$, $4.09\left(4 \mathrm{H}, \mathrm{m}, \mathrm{CH}_{2}\right), 4.18$ (2H, m, CH-OH), 6.85 (4H, m, CH-aromatic), 7.18 (4H, m, CH-aromatic); ${ }^{13} \mathrm{C}$ $\operatorname{NMR}\left(\mathrm{CDCl}_{3}\right)$, ppm: $\delta 31.0,41.8,45.9,53.4,69.0,69.4,114.0,127.9,143.9,156.0$

Synthesis of 1-(prop-2-yn-1-yloxy)-2,2-bis((prop-2-yn-1-yloxy)methyl)butane (AK): A solution of 1,1,1-tris(hydroxymethyl)propane (14.7 mmol, $1.97 \mathrm{~g})$ and $40 \mathrm{w} / \mathrm{w} \% \mathrm{NaOH} /$ water $(10 \mathrm{ml})$ in DMSO (15 $\mathrm{ml}$ ) was added in a round bottom flask and stirred for $1 \mathrm{~h}$ at room temperature. After dropwise addition of propargyl bromide ( $94 \mathrm{mmol}, 8.9 \mathrm{ml}$ of $80 \%$ solution in toluene), the reaction mixture was stirred for 5 days. The product was extracted with diethyl ether and water, dried with $\mathrm{Na}_{2} \mathrm{SO}_{4}$, purified by column chromatography using a hexane:ethyl acetate mixture as eluent, and dried in vacuo as a colorless oil. 
(72\% yield) ${ }^{1} \mathrm{H}$ NMR $\left(\mathrm{CDCl}_{3}\right)$, ppm: $\delta 0.88\left(3 \mathrm{H}, \mathrm{t}, \mathrm{CH}_{3}\right), 1.42\left(2 \mathrm{H}, \mathrm{q}, \mathrm{CH}_{2}-\mathrm{CH}_{3}\right) 2.42(3 \mathrm{H}, \mathrm{t}$, alkyne-H), $3.40\left(6 \mathrm{H}, \mathrm{s}, \mathrm{CH}_{2}\right), 4.11\left(6 \mathrm{H}, \mathrm{s}, \mathrm{CH}_{2}\right.$-alkyne); ${ }^{13} \mathrm{C} \mathrm{NMR}\left(\mathrm{CDCl}_{3}\right), \mathrm{ppm}: \delta$ 7.5, 22.7, 42.7, 58.6, 70.3, 74.0, 80.1

Synthesis of prop-2-yn-1-yl (3-(triethoxysilyl)propyl)carbamate (Si-AK): A solution of 3(triethoxysilyl)propyl isocyanate $(40.4 \mathrm{mmol}, 10 \mathrm{ml})$ and dibutyltin dilaurate (5 drops) in THF (45 mL) was added in a round bottom flask and purged under nitrogen. The reaction mixture was cooled to $0^{\circ} \mathrm{C}$ in an ice bath, followed by dropwise addition of propargyl alcohol (40.4 mmol, $2.39 \mathrm{ml})$. Removal of the ice bath allowed the reaction mixture to stir at room temperature for $12 \mathrm{~h}$. The reaction mixture was then flowed through a silica plug with excess THF and purified by column chromatography using a hexane:ethyl acetate mixture as eluent. The product was dried in vacuo as a colorless oil. (95\% yield) ${ }^{1} \mathrm{H}$ NMR $\left(\mathrm{CDCl}_{3}\right)$, ppm: $\delta 0.65\left(2 \mathrm{H}, \mathrm{t}, \mathrm{Si}-\mathrm{CH}_{2}\right), 1.24\left(9 \mathrm{H}, \mathrm{t}, \mathrm{CH}_{3}, \mathrm{t}\right), 1.64\left(2 \mathrm{H}\right.$, quint, $\left.\mathrm{CH}_{2}\right), 2.47(1 \mathrm{H}, \mathrm{t}$, alkyne-H), $3.21\left(2 \mathrm{H}, \mathrm{q}, \mathrm{CH}_{2}\right), 3.84\left(6 \mathrm{H}, \mathrm{q}, \mathrm{CH}_{2}-\mathrm{CH}_{3}\right), 4.68\left(2 \mathrm{H}, \mathrm{s}, \mathrm{CH}_{2}\right.$-alkyne); ${ }^{13} \mathrm{C} \mathrm{NMR}\left(\mathrm{CDCl}_{3}\right)$, ppm: $\delta 7.6,18.3,23.2,43.5,52.3,58.5,74.4,78.4,155.4$

Preparation of $\mathrm{CuCl}_{2}$ [PMDETA] complex: 1:1 molar mixture of $\mathrm{CuCl}_{2}$ and PMDETA $\left(\mathrm{N}, \mathrm{N}, \mathrm{N}^{\prime}, \mathrm{N}^{\prime}, \mathrm{N}^{\prime \prime}-\right.$ pentamethyldiethylenetriamine) in acetonitrile was stirred overnight at room temperature and dried in vacuo to a blue-green solid.

2. Methods

BisGMA/TEGDMA sample preparation. A BisGMA:TEGDMA (70:30 weight ratio) mixture with 0.6 weight percentage of CQ and 1.6 weight percentage of EDAB was prepared by physical mixing.

CUAAC sample preparation. Stoichiometric mixtures of a diazide, trialkyne (a mole ratio of 1:1 to $\mathrm{N}_{3}$ :alkyne), with 2 mole percentage of $\mathrm{CuCl}_{2}$ [PMDETA] per functionality, 0.6 weight percentage of CQ, 1.6 weight percentage of EDAB were prepared. Methanol was added to homogenize the mixture and later removed in vacuo. Any residual solvent content of each resin was verified by ${ }^{1} \mathrm{H}-\mathrm{NMR}$ using a 
Bruker Avance-III $400 \mathrm{MHz}$ spectrometer with 16 scans and $1 \mathrm{~s}$ of relaxation time. For all experiments, methanol concentration was $<0.5 \mathrm{wt} \%$.

Fourier Transform Infrared Spectroscopy. An FTIR spectrometer (Nicolet 6700) connected to a tensometer via fiber optic cables was used to monitor the real-time polymerization kinetics of the functional group conversion. Samples were placed between two cylindrical quartz rods, and light was irradiated from the bottom rod using a light guide connected to a mercury lamp (Acticure 4000, EXFO) with 400-500 nm bandgap filter. A radiometer (Model 100, Demetron Research) was used to measure the output power density of the lamp. The overtone signal of the alkyne was monitored between 6538$6455 \mathrm{~cm}^{-1}$, and the overtone signal of the methacrylate was measured between $6250-6096 \mathrm{~cm}^{-1}$.

Polymerization shrinkage stress measurement. A tensometer (American Dental Association Health Foundation, ADAHF-PRC) was utilized to monitor polymerization post-gel shrinkage stress using cantilever beam deflection theory [63] with in situ polymerization kinetics [64]. The sample (6mm in diameter, $1 \mathrm{~mm}$ in thickness) was placed in a cavity between two cylindrical quartz rods, which were previously treated with silane (methacrylate silane coupling agent or $\mathrm{Si}-\mathrm{AK}$ ) to improve the interfacial adhesion, and sealed with a polytetrafluoroethylene (PTFE) sleeve to prevent oxygen inhibition. Light was transmitted through the bottom rod using a light guide connected to a mercury lamp (Acticure 4000, EXFO) with a 400-500 nm bandgap filter. The deflection of the aluminum beam, caused by a tensile force exerted with bonded sample shrinkage, was measured with a linear variable differential transformer (LVDT) and converted to stress based upon beam calibration constant and cross-sectional area of the sample. A simultaneous measurement of functional group conversion with polymerization shrinkage stress by fiber optic cables was recorded for $15 \mathrm{~min}$.

Dynamic volumetric shrinkage measurement. A linometer (Academic Center for Dentistry Amsterdam, ACTA) was used to measure dynamic volumetric shrinkage [65]. The sample (6mm in diameter, $1.5 \mathrm{~mm}$ in thickness) was placed between a fixed upper glass slide and a movable aluminum disc, which were 
previously treated with grease. The dynamic volumetric shrinkage was obtained from the displacement of aluminum disc by a linear variable differential transformer (LVDT). The light was irradiated from 5 $\mathrm{cm}$ above the top of the upper glass slide using a light guide connected to a mercury lamp (Acticure 4000, EXFO) with 400-500 nm bandgap filter. A simultaneous measurement of functional group conversion with FTIR by fiber optic cables was recorded for $15 \mathrm{~min}$.

Density measurement. A multipycnometer (Quantachrome instruments) was used to measure the density of monomer mixtures and polymer samples. Each sample with known mass was placed in a $4.5 \mathrm{~cm}^{3}$ cell and pressurized with helium gas. The release of pressure resulted in the volume expansion of helium gas, which was converted to density of the sample. Equivalent polymer discs made from dynamic volumetric shrinkage measurement were used. Functional group conversion was monitored from FT-IR during the polymerization.

Dynamic mechanical analysis. A DMA Q800 (TA instruments) in multi-frequency-strain mode with frequency of $1 \mathrm{~Hz}$ and a heating rate of $3{ }^{\circ} \mathrm{C} \min ^{-1}$ was used to measure the storage modulus and the glass transition temperature $\left(\mathrm{T}_{\mathrm{g}}\right.$ ), which was taken as the peak of the $\tan \delta$ (a ratio of E'/E': the storage and loss moduli) curve. $350 \mathrm{~mW} \mathrm{~cm}^{-2}$ of 400-500nm light, connected to a mercury lamp (Acticure 4000, EXFO) by a light guide with a collimator, was incident for $120 \mathrm{~s}$ at room temperature on one side of the sample and immediately inverted to cure for $120 \mathrm{~s}$ on the opposite side of the sample. The rectangular dimensions of each sample specimen were $1 \times 2 \times 25 \mathrm{~mm}(\mathrm{t} \times \mathrm{w} \times \mathrm{l})$. The functional group conversion was recorded via FTIR spectra prior to and immediately after the polymerization.

Three point flexural test. Three-point bend (MTS 858 Mini Bionix II) with a strain rate of $1 \mathrm{~mm} \mathrm{~min}^{-1}$ and a span of $20 \mathrm{~mm}$ was used to obtain flexural modulus, flexural strength, and flexural toughness. Photo-activation provided $350 \mathrm{~mW} \mathrm{~cm} \mathrm{~cm}^{-2}$ of00-500nm light from a mercury lamp (Acticure 4000, EXFO) by a light guide with a collimator. The irradiation was conducted for $120 \mathrm{~s}$ at room temperature on one side of the sample followed by immediate inversion to cure for $120 \mathrm{~s}$ on the opposite side of the 
sample. The rectangular dimensions of each sample specimen were $2 \times 2 \times 25 \mathrm{~mm}(\mathrm{t} \times \mathrm{w} \times \mathrm{l})$. Functional group conversion was recorded via FTIR spectra prior to and immediately after the polymerization.

Statistical analysis. Statistical analysis of the experiments was performed via one-way analysis of variance (ANOVA), and multiple pair-wise comparisons were conducted via Tukey's test with a significance level of 0.05 . The number of repetitions for each experiment were as follow: dynamic mechanical analysis $(n=3)$, polymerization shrinkage stress $(n=3)$, dynamic volumetric shrinkage $(n=4)$, three point flexural test $(n=5)$, density measurement $(n=3)$.

\section{RESULTS AND DISCUSSION}

In situ polymerization kinetics of the $\mathrm{CuAAC}$ polymerization and dimethacrylate polymerization using resin formulations in Fig. 1 during 5 min reaction time is presented using $500 \mathrm{~mW} \mathrm{~cm}^{-2}$ of 400 500nm light for $90 \mathrm{~s}$ irradiation (Figure 2). Both CuAAC resins, labeled as BZ-AZ and BPA-AZ, demonstrated an induction period of $30 \mathrm{~s}$ at the beginning of polymerization. Contrarily, a BisGMA/TEGDMA resin initiated immediately after light exposure. In spite of faster initial rate of BisGMA-based dimethacrylate polymerization, only $75 \%$ maximum conversion was achieved for BisGMA/TEGDMA while BZ-AZ and BPA-AZ yielded higher maximum conversions of 99\% and $80 \%$, respectively, after $90 \mathrm{~s}$ of light irradiation. The limited maximum conversion obtained from each resin system was due to vitrification where $T_{\text {cure }}$ was lower than $T_{g}$ at given conversion (Table 1 ). In the case of BZ-AZ, nearly quantitative conversion was achieved within a few minutes due to reaction exotherm generated from $\mathrm{CuAAC}$ polymerization enhanced mobility of the resin and the presence of the persistent copper(I) catalyst continuously promoting CuAAC polymerization.

[Figure 2]

To analyze the thermo-mechanical properties of the polymer made from each resin system utilized in Fig. 2, the storage modulus at $40{ }^{\circ} \mathrm{C}$ and glass transition temperature $\left(\mathrm{T}_{\mathrm{g}}\right)$ were measured via DMA (Table 1). The maximum conversion of each sample was first recorded via FTIR immediately 
after light exposure, and the sample was then placed in the DMA to measure the storage modulus and $T_{\mathrm{g}}$. The $1^{\text {st }}$ cycle of the DMA showed the storage modulus and $T_{g}$ at given conversion measured from FTIR while the $2^{\text {nd }}$ cycle exhibited enhanced storage modulus and $T_{g}$ after the thermal cycle. From the $1^{\text {st }}$ cycle, all three samples showed similar storage modulus around $2.3 \mathrm{GPa}$ at $40{ }^{\circ} \mathrm{C}$ and exhibited $\mathrm{T}_{\mathrm{g}}$ at least $40{ }^{\circ} \mathrm{C}$ above ambient temperature, indicative of glassy state at ambient temperature. BZ-AZ, BPAAZ, and BisGMA/TEGDMA yielded $\mathrm{T}_{\mathrm{g}}$ of $62{ }^{\circ} \mathrm{C}, 87{ }^{\circ} \mathrm{C}$, and $160{ }^{\circ} \mathrm{C}$ at $\sim 99 \%, 87 \%$, and $74 \%$ conversion, respectively. BisGMA/TEGDMA exhibited two $\mathrm{T}_{\mathrm{g}}$ domains at the $1^{\text {st }}$ cycle due to the presence of unreacted free or pendant monomers/oligomers from incomplete conversion combined with heterogeneity of network developed from chain-growth polymerization, and the lower $\mathrm{T}_{\mathrm{g}}$ domain completely disappeared at the $2^{\text {nd }}$ cycle due to additional cure during thermal cycle. As expected in a step-growth polymer network, a narrow transition from the glassy to the rubbery state was observed in CuAAC polymers indicative of network homogeneity as opposed to a chain-growth BisGMA-based polymer which displayed a broad $\mathrm{T}_{\mathrm{g}}$ over a wide range of temperature (Figure $\mathrm{S} 1-\mathrm{S} 2$ ). Only BZ-AZ was able to achieve complete conversion without the thermally assisted post-cure under the standardized reaction conditions used. Achieving high conversion can eliminate issues related to extractable monomers in dental resins.

\section{[Table 1]}

Maximum polymerization shrinkage stress and dynamic volumetric shrinkage of each resin system were compared with reference to functional group conversion (Table 2). From polymerization shrinkage stress measurement, BZ-AZ and BPA-AZ showed 3 and 4 times lower shrinkage stress, $0.43 \pm 0.05 \mathrm{MPa}$ at $98 \pm 0.3 \%$ conversion and $0.27 \pm 0.02 \mathrm{MPa}$ at $83 \pm 4 \%$ conversion, respectively, when compared to BisGMA/TEGDMA, which yielded a stress of $1.3 \pm 0.07 \mathrm{MPa}$ at $75 \pm 3 \%$ conversion. In addition, dynamic volumetric shrinkage measurements performed on the equivalent resin formulations showed that BZ-AZ and BPA-AZ generated $6.2 \pm 0.3 \%$ volumetric shrinkage at $97 \pm 1 \%$ conversion and 
$6.4 \pm 0.5 \%$ volumetric shrinkage at $87 \pm 0.2 \%$ conversion, respectively, while BisGMA/TEGDMA exhibited $7 \pm 0.07 \%$ volumetric shrinkage at $76 \pm 3 \%$ conversion. Despite the relatively high volumetric shrinkage obtained from the CuAAC polymerization, the delayed gelation in a step-growth polymerization leads to stress reduction due to viscous flow in the lower conversion regime up to gelpoint conversion of $\sim 71 \%$. This delay enabled the CuAAC polymers to generate low shrinkage stress at quantitative conversion. It is worth noting that the higher initial viscosity of BPA-AZ resin as compared to $\mathrm{BZ}-\mathrm{AZ}$ led to a temperature increase inside a $\sim 1.5 \mathrm{~mm}$ thick sample. In order to minimize this adiabatic reaction condition, only $60 \mathrm{~s}$ of light was used for the BPA-AZ in volumetric shrinkage measurement. However, this exotherm becomes modest by reducing reactive functional group density when a composite formulation is utilized and still provides mobility to enhance the maximum conversion for CuAAC polymerization.

In addition, the volumetric shrinkage per mole of converted functional groups (alkyne or azide functionality for CuAAC polymerization and double bond functionality for dimethacrylate polymerization) was calculated based on our assumption that dynamic volumetric shrinkage obtained from linometer represents total volumetric shrinkage including both pre-gel and post-gel regime. From the calculation, relatively similar volumetric shrinkage per one mole of functional groups between 20 and $22 \mathrm{ml}$ shrinkage/mol of functionality was obtained for all three resin systems, consistent with that originally found for methacrylate [66]. In order to determine the molar volumetric shrinkage moreprecisely, a multipycnometer was used to measure the density of each monomer mixture and the polymer sample obtained from the linometer experiment (Table S3). The density difference between monomers and polymers was then converted to molar volumetric shrinkage. As a result, BisGMA/TEGDMA and BZ-AZ showed molar shrinkage of approximately $21 \mathrm{ml}$ per double bond and $25 \mathrm{ml}$ per triple bond, respectively, which were in a good agreement with the linometer experiment. The molar shrinkage generated from $\mathrm{CuAAC}$ polymerization was caused by not only a five-member ring 
formation from each alkyne and azide functional group but also the development of secondary interactions associated with highly crosslinked triazoles.

[Table 2]

In order to illustrate the effect of gelation on polymerization shrinkage stress, the evolution of polymerization shrinkage stress with respect to functional group conversion in CuAAC polymerizations was compared with a BisGMA-based dimethacrylate polymerization at varying light intensities (Figure 3). Each resin mixture was irradiated for $90 \mathrm{~s}$ using different light intensities ranging from $100 \mathrm{~mW} \mathrm{~cm}^{-2}$ to $500 \mathrm{~mW} \mathrm{~cm}^{-2}$, and the final polymerization shrinkage stress was measured for 10 minutes of reaction time using the tensometer. A gradual increase in light intensity from $100 \mathrm{~mW} \mathrm{~cm} \mathrm{co}^{-2}$ to $500 \mathrm{~mW} \mathrm{~cm}^{-2}$ influenced the final conversion acquired after $10 \mathrm{~min}$ reaction time as well as the corresponding final polymerization shrinkage stress. For a BisGMA-based resin, the double bond conversion was increased from $65 \%$ to $75 \%$, and the corresponding shrinkage stress was incremented from $1 \mathrm{MPa}$ to $1.3 \mathrm{MPa}$. For a $\mathrm{CuAAC}$ resin, the triple bond conversion was increased from $70 \%$ to $100 \%$, and the corresponding shrinkage stress escalated from 0 MPa to $0.45 \mathrm{MPa}$. Since the theoretical gel-point conversion for a step-growth polymerization using difunctional and trifunctional monomers was approximately $71 \%$ using the following equation: $\frac{1}{\sqrt{\left\{r \cdot\left(f_{a}-1\right) \cdot\left(f_{b}-1\right)\right\}}}$, where $r=\frac{[a]_{0}}{[b]_{0}}=1$ [67], no significant polymerization shrinkage stress was developed in the CuAAC resin below $80 \%$ conversion. Upon gelation, shrinkage stress of both CuAAC and dimethacrylate polymerization increased significantly with conversion. This delayed gelation in CuAAC polymerization resulted in dramatically reduced shrinkage stress in contrast to BisGMA-based resin system which has less than 5\% gel-point conversion $[29,68]$.

[Figure 3]

Similarly, the evolution of volumetric shrinkage with respect to functional group conversion in CuAAC polymerizations as compared to BisGMA-based dimethacrylate polymerization is also addressed by varying light intensity (Figure 4). In order to correlate dynamic volumetric shrinkage with 
polymerization shrinkage stress, the irradiation conditions used were similar to those used to evaluate shrinkage stress. Each resin mixture was irradiated for 90 seconds using different light intensities ranging from $100 \mathrm{~mW} \mathrm{~cm}^{-2}$ to $500 \mathrm{~mW} \mathrm{~cm}^{-2}$, and the final polymerization shrinkage was measured after 5 minutes reaction time using a linometer. As a result, the CuAAC polymerization exhibited a linear relationship between conversion and volumetric shrinkage above a gel-point conversion around $71 \%$. Specifically, the volumetric shrinkage increased from $0 \%$ at $70 \%$ conversion to $5.8 \%$ at $98 \%$ conversion. This maximum volumetric shrinkage of $5.8 \%$ at quantitative conversion in $\mathrm{CuAAC}$ polymerization was similar to the maximum shrinkage obtained from BisGMA-based dimethacrylate polymerization.

[Figure 4]

As modulus is one of the contributing factors for shrinkage stress development, three-point bending was performed using a universal testing machine (MTS) to analyze flexural modulus, flexural strength, and flexural toughness of both $\mathrm{CuAAC}$ and BisGMA-based polymers. Final conversion of each sample specimen was monitored via FTIR immediately after polymerization, and all mechanical tests were performed within 4 days after polymerization with the specimens stored in the dark at room temperature. Fig. 5 and Table 3 present a representative stress-strain curve and the summary of values obtained from three-point bend experiment. Flexural modulus and flexural strength were calculated using the following equations (1) and (2):

$E=\frac{\mathrm{FL}^{3}}{4 \mathrm{BH}^{3} \mathrm{~d}}$

$\sigma=\frac{3 \mathrm{FL}}{2 \mathrm{BH}^{2}}$

where $\mathrm{F}$ is the maximum load, $\mathrm{L}$ is the length of span, $\mathrm{B}$ is the width of the sample specimen, $\mathrm{H}$ is the height of the sample specimen, $\mathrm{d}$ is the extension corresponding to the load $\mathrm{F}$ [69]. Furthermore, flexural toughness was calculated up to stress at break for BisGMA/TEGDMA. However, for BZ-AZ, 
the samples were sufficiently tough that no fracture was observed to the point the sample lost horizontal contact with the fixture; therefore, for these experimental samples, the energy to reach a strain of $11 \%$, where stress reached $\sim 60 \%$ of the stress maximum, was chosen to compare relative toughness values. As a result, considerably higher toughness coupled with a relatively high initial stiffness was observed for the CuAAC polymers as compared with BisGMA-based polymers. At $~ 99 \%$ conversion, BZ-AZ exhibited approximately 15-25\% lower flexural modulus around $2.5 \mathrm{GPa}$ and flexural strength around $117 \mathrm{MPa}$ compared with BisGMA/TEGDMA at $76 \%$ conversion. However, BZ-AZ showed significantly higher energy uptake upon deformation when compared with BisGMA/TEGDMA polymer. Approximately 7.1 $\mathrm{MJ} \mathrm{m}^{-3}$ of energy was absorbed by BZ-AZ when strained to $11 \%$ whereas only $2.7 \mathrm{MJ} \mathrm{m}^{-3}$ of energy was absorbed by BisGMA/TEGDMA before fracture at $\sim 4.5 \%$ strain, giving the advantage of excellent strength yet reduced brittleness in CuAAC polymers.

[Figure 5]

' $[$ Table 3]

\section{CONCLUSIONS}

Photo-CuAAC polymerizations are capable of achieving high to complete conversion upon light irradiation on the minutes time scale while forming tough, glassy, low stress homogeneous glassy crosslinked networks at ambient temperature. CuAAC polymers exhibit a dramatic ability to absorb energy without fracturing and considerably reduced polymerization shrinkage stress. Although photo$\mathrm{CuAAC}$ polymerization has a somewhat slower polymerization rate under these conditions, comparable volumetric shrinkage, and moderate flexural modulus compared with methacrylate-based free radical photopolymerization, central mechanical failures in practical dental restoratives emerge from brittleness and high polymerization shrinkage stress, highlighting the significance of low stress generating tough CuAAC polymers.

\section{ACKNOWLEDGEMENTS}


The authors acknowledge financial support from the National Institutes of Health

(NIH:5UO1DE023774) and the National Science Foundation (NSF:CHE1214109). The authors thank to

Steven Lewis for the help with linometer, MTS, and multipycnometer.

\section{REFERENCES}

[1] Cramer NB, Stansbury JW, Bowman CN. Recent advances and developments in composite dental restorative materials. J Dent Res 2011;90:402-16. doi:10.1177/0022034510381263.

[2] Braga RR, Ballester RY, Ferracane JL. Factors involved in the development of polymerization shrinkage stress in resin-composites: A systematic review. Dent Mater 2005;21:962-70. doi:10.1016/j.dental.2005.04.018.

[3] Abu-Elenain DA, Lewis SH, Stansbury JW. Property evolution during vitrification of dimethacrylate photopolymer networks. Dent Mater 2013;29:1173-81. doi:10.1016/j.dental.2013.09.002.

[4] Gonçalves F, Kawano Y, Pfeifer C, Stansbury JW, Braga RR. Influence of BisGMA, TEGDMA, and BisEMA contents on viscosity, conversion, and flexural strength of experimental resins and composites. Eur J Oral Sci 2009;117:442-6. doi:10.1111/j.1600-0722.2009.00636.x.

[5] Charton C, Falk V, Marchal P, Pla F, Colon P. Influence of Tg, viscosity and chemical structure of monomers on shrinkage stress in light-cured dimethacrylate-based dental resins. Dent Mater 2007;23:1447-59. doi:DOI 10.1016/j.dental.2007.05.017.

[6] Gonçalves F, Pfeifer CCS, Stansbury JW, Newman SM, Braga RR. Influence of matrix composition on polymerization stress development of experimental composites. Dent Mater 2010;26:697-703. doi:10.1016/j.dental.2010.03.014.

[7] Braga RR, Ferracane JL. Contraction Stress Related to Degree of Conversion and Reaction Kinetics. J Dent Res 2002;81:114-8. 
[8] Feng L, Suh BI. A mechanism on why slower polymerization of a dental composite produces lower contraction stress. J Biomed Mater Res Part B Appl Biomater 2006;78:63-9.

[9] Stansbury JW, Trujillo-Lemon M, Lu H, Ding X, Lin Y, Ge J. Conversion-dependent shrinkage stress and strain in dental resins and composites. Dent Mater 2005;21:56-67. doi:10.1016/j.dental.2004.10.006.

[10] Watts DC, Satterthwaite JD. Axial shrinkage-stress depends upon both C-factor and composite mass. Dent Mater 2008;24:1-8. doi:10.1016/j.dental.2007.08.007.

[11] Mantri SP, Mantri SS. Management of Shrinkage Stresses in Direct Restorative Light-Cured Composites: A Review. J Esthet Restor Dent 2013;25:305-13. doi:10.1111/jerd.12047.

[12] Matsukawa S, Hayakawa T, Nemoto K. Development of high-toughness resin for dental applications. Dent Mater 1994;10:343-6.

[13] Gonçalves F, Azevedo CLN, Ferracane JL, Braga RR. BisGMA/TEGDMA ratio and filler content effects on shrinkage stress. Dent Mater 2011;27:520-6. doi:10.1016/j.dental.2011.01.007.

[14] Shah PK, Stansbury JW. Role of filler and functional group conversion in the evolution of properties in polymeric dental restoratives. Dent Mater 2014;30:586-93. doi:10.1016/j.dental.2014.02.015.

[15] Condon JR, Ferracane JL. Reduction of composite contraction stress through non-bonded microfiller particles. Dent Mater 1998;14:256-60. doi:10.1016/S0109-5641(98)00036-0.

[16] Liu J, Howard GD, Lewis SH, Barros MD, Stansbury JW. A study of shrinkage stress reduction and mechanical properties of nanogel-modified resin systems. Eur Polym J 2012;48:1819-28. doi:10.1016/j.eurpolymj.2012.08.009.

[17] Moraes RR, Garcia JW, Barros MD, Lewis SH, Pfeifer CS, Liu J, et al. Control of polymerization shrinkage and stress in nanogel-modified monomer and composite materials. Dent Mater 
2011;27:509-19. doi:10.1016/j.dental.2011.01.006.

[18] Carioscia JA, Lu H, Stanbury JW, Bowman CN. Thiol-ene oligomers as dental restorative materials. Dent Mater 2005;21:1137-43. doi:10.1016/j.dental.2005.04.002.

[19] Lee M-R, Cho B-H, Son H-H, Um C-M, Lee I-B. Influence of cavity dimension and restoration methods on the cusp deflection of premolars in composite restoration. Dent Mater 2007;23:28895. doi:10.1016/j.dental.2006.01.025.

[20] Lim BS, Ferracane JL, Sakaguchi RL, Condon JR. Reduction of polymerization contraction stress for dental composites by two-step light-activation. Dent Mater 2002;18:436-44. doi:10.1016/S0109-5641(01)00066-5.

[21] Ge J, Trujillo M, Stansbury J. Synthesis and photopolymerization of low shrinkage methacrylate monomers containing bulky substituent groups. Dent Mater 2005;21:1163-9. doi:10.1016/j.dental.2005.02.002.

[22] Khatri CA, Stansbury JW, Schultheisz CR, Antonucci JM. Synthesis, characterization and evaluation of urethane derivatives of Bis-GMA. Dent Mater 2003;19:584-8. doi:10.1016/S01095641(02)00108-2.

[23] Lu H, Trujillo-Lemon M, Ge J, Stansbury JW. Dental resins based on dimer acid dimethacrylates: a route to high conversion with low polymerization shrinkage. Compend Contin Educ Dent (Jamesburg, NJ 1995) 2010;31:1-4.

[24] Szczepanski CR, Stansbury JW. Stress reduction in phase-separated, cross-linked networks: Influence of phase structure and kinetics of reaction. J Appl Polym Sci 2014;131:40879. doi:10.1002/app.40879.

[25] Lu H, Carioscia J a, Stansbury JW, Bowman CN. Investigations of step-growth thiol-ene polymerizations for novel dental restoratives. Dent Mater 2005;21:1129-36. 
doi:10.1016/j.dental.2005.04.001.

[26] Cramer NB, Couch CL, Schreck KM, Carioscia JA, Boulden JE, Stansbury JW, et al. Investigation of thiol-ene and thiol-ene-methacrylate based resins as dental restorative materials. Dent Mater 2010;26:21-8. doi:10.1016/j.dental.2009.08.004.

[27] Podgórski M, Becka E, Claudino M, Flores A, Shah PK, Stansbury JW, et al. Ester-free thiol-ene dental restoratives-Part A : resin development. Dent Mater 2015;31:1255-62.

[28] Schreck KM, Leung D, Bowman CN. Hybrid Organic/Inorganic Thiol-Ene-Based Photopolymerized Networks. Macromolecules 2011;44:7520-9.

[29] Pfeifer CS, Wilson ND, Shelton ZR, Stansbury JW. Delayed gelation through chain-transfer reactions: Mechanism for stress reduction in methacrylate networks. Polymer (Guildf) 2011;52:3295-303. doi:10.1016/j.polymer.2011.05.034.

[30] Soh MS, Yap AUJ, Sellinger A. Physicomechanical evaluation of low-shrinkage dental nanocomposites based on silsesquioxane cores. Eur J Oral Sci 2007;115:230-8. doi:10.1111/j.1600-0722.2007.00449.x.

[31] Eick JD, Kotha SP, Chappelow CC, Kilway K V., Giese GJ, Glaros AG, et al. Properties of silorane-based dental resins and composites containing a stress-reducing monomer. Dent Mater 2007;23:1011-7. doi:10.1016/j.dental.2006.09.002.

[32] Contreras PP, Tyagi P, Agarwal S. Low volume shrinkage of polymers by photopolymerization of 1,1-bis(ethoxycarbonyl)-2-vinylcyclopropanes. Polym Chem 2015;6:2297-304. doi:10.1039/C4PY01705F.

[33] Kloxin CJ, Scott TF, Bowman CN. Stress Relaxation via Addition-Fragmentation Chain Transfer in a Thiol-ene Photopolymerization. Macromolecules 2009;42:2551-6.

[34] Park HY, Kloxin CJ, Abuelyaman AS, Oxman JD, Bowman CN. Novel dental restorative 
materials having low polymerization shrinkage stress via stress relaxation by additionfragmentation chain transfer. Dent Mater 2012;28:1113-9. doi:10.1016/j.dental.2012.06.012.

[35] Park HY, Kloxin CJ, Scott TF, Bowman CN. Covalent adaptable networks as dental restorative resins: Stress relaxation by addition-fragmentation chain transfer in allyl sulfide-containing resins. Dent Mater 2010;26:1010-6. doi:10.1016/j.dental.2010.06.007.

[36] Rostovtsev V V., Green LG, Fokin V V., Sharpless KB. A stepwise huisgen cycloaddition process: Copper(I)-catalyzed regioselective "ligation" of azides and terminal alkynes. Angew Chemie - Int Ed 2002;41:2596-9. doi:10.1002/1521-3773(20020715)41:14<2596::AIDANIE2596>3.0.CO;2-4.

[37] Tornøe CW, Christensen C, Meldal M. Peptidotriazoles on solid phase: [1,2,3]-Triazoles by regiospecific copper(I)-catalyzed 1,3-dipolar cycloadditions of terminal alkynes to azides. J Org Chem 2002;67:3057-64. doi:10.1021/jo011148j.

[38] Barner-Kowollik C, Du Prez FE, Espeel P, Hawker CJ, Junkers T, Schlaad H, et al. "Clicking” polymers or just efficient linking: What is the difference? Angew Chemie - Int Ed 2011;50:60-2. doi:10.1002/anie.201003707.

[39] Kolb HC, Finn MG, Sharpless KB. Click Chemistry: Diverse Chemical Function from a Few Good Reactions. Angew Chemie - Int Ed 2001;40:2004-21. doi:10.1002/15213773(20010601)40:11<2004::AID-ANIE2004>3.0.CO;2-5.

[40] Iha RK, Wooley KL, Nyström AM, Burked DJ, Kade MJ, Hawker CJ. Applications of orthogonal "Click" Chemistries in the synthesis of functional soft materials. Chem Rev 2009;109:5620-86. doi:10.1021/cr900138t.

[41] Reuther JF, Siriwardane D a., Kulikov O V., Batchelor BL, Campos R, Novak BM. Facile Synthesis of Rod-Coil Block Copolymers with Chiral, Helical Polycarbodiimide Segments via Postpolymerization CuAAC "Click" Coupling of Functional End Groups. Macromolecules 
2015;48:3207-16. doi:10.1021/acs.macromol.5b00453.

[42] Wang Y, Salmon L, Ruiz J, Astruc D. Metallodendrimers in three oxidation states with electronically interacting metals and stabilization of size-selected gold nanoparticles. Nat Commun 2014;5:3489. doi:10.1038/ncomms4489.

[43] Meldal M. Polymer “clicking” by CuAAC reactions. Macromol Rapid Commun 2008;29:101651. doi:10.1002/marc.200800159.

[44] Hong V, Presolski SI, Ma C, Finn MG. Analysis and optimization of copper-catalyzed azidealkyne cycloaddition for bioconjugation. Angew Chemie - Int Ed 2009;48:9879-83. doi:10.1002/anie.200905087.

[45] Mckay CS, Finn MG. Click Chemistry in Complex Mixtures : Bioorthogonal Bioconjugation. Chem Biol 2014;21:1075-101.

[46] Díaz Velázquez H, Ruiz García Y, Vandichel M, Madder A, Verpoort F. Water-soluble NHC-Cu catalysts: applications in click chemistry, bioconjugation and mechanistic analysis. Org Biomol Chem 2014;12:9350-6. doi:10.1039/C4OB01350F.

[47] Vutti S, Buch-Månson N, Schoffelen S, Bovet N, Martinez KL, Meldal M. Covalent and Stable CuAAC Modification of Silicon Surfaces for Control of Cell Adhesion. ChemBioChem 2015;16:782-91. doi:10.1002/cbic.201402629.

[48] Smyth T, Petrova K, Payton NM, Persaud I, Redzic JS, Graner MW, et al. Surface Functionalization of Exosomes Using Click Chemistry. Bioconjug Chem 2014;25:1777-84.

[49] Canalle LA, Van Berkel SS, De Haan LT, Van Hest JCM. Copper-free clickable coatings. Adv Funct Mater 2009;19:3464-70. doi:10.1002/adfm.200900743.

[50] Ritter SC, Konig B. Signal amplification and transduction by photo-activated catalysis. Chem Commun 2006:4694-6. doi:10.1039/b610696j. 
[51] Adzima BJ, Tao Y, Kloxin CJ, DeForest C a, Anseth KS, Bowman CN. Spatial and temporal control of the alkyne-azide cycloaddition by photoinitiated $\mathrm{Cu}(\mathrm{II})$ reduction. Nat Chem 2011;3:256-9. doi:10.1038/nchem.980.

[52] Tasdelen MA, Yagci Y. Light-induced copper(I)-catalyzed click chemistry. Tetrahedron Lett 2010;51:6945-7. doi:10.1016/j.tetlet.2010.10.166.

[53] Díaz DD, Punna S, Holzer P, Mcpherson AK, Sharpless KB, Fokin V V., et al. Click chemistry in materials synthesis. 1 . Adhesive polymers from copper-catalyzed azide-alkyne cycloaddition. J Polym Sci Part A Polym Chem 2004;42:4392-403. doi:10.1002/pola.20330.

[54] LIU Y, DI’AZ DD, ACCURSO AA, SHARPLESS KB, FOKIN V V., FINN MG. Click Chemistry in Materials Synthesis. III. Metal-Adhesive Polymers from Cu(I)-Catalyzed AzideAlkyne Cycloaddition. J Polym Sci Part A Polym Chem 2007;45:5182-9. doi:10.1002/pola.22262.

[55] Wei Q, Wang J, Shen X, Zhang XA, Sun JZ, Qin A, et al. Self-healing hyperbranched poly(aroyltriazole)s. Sci Rep 2013;3:1093. doi:10.1038/srep01093.

[56] Tang Y, Jim CKW, Liu Y, Ye L, Qin A, Lam JWY, et al. Synthesis and curing of hyperbranched poly(triazole)s with click polymerization for improved adhesion strength. ACS Appl Mater Interfaces 2010;2:566-74. doi:10.1021/am9008727.

[57] McBride MK, Gong T, Nair DP, Bowman CN. Photo-mediated copper(I)-catalyzed azide-alkyne cycloaddition (CuAAC) "click" reactions for forming polymer networks as shape memory materials. Polym (United Kingdom) 2014;55:5880-4. doi:10.1016/j.polymer.2014.08.001.

[58] Song S, Ko Y-G, Lee H, Wi D, Ree BJ, Li Y, et al. High-performance triazole-containing brush polymers via azide-alkyne click chemistry: a new functional polymer platform for electrical memory devices. NPG Asia Mater 2015;7:e228. doi:10.1038/am.2015.130. 
[59] Gong T, Adzima BJ, Baker NH, Bowman CN. Photopolymerization reactions using the photoinitiated copper (I)-catalyzed azide-alkyne cycloaddition (CuAAC) reaction. Adv Mater 2013;25:2024-8. doi:10.1002/adma.201203815.

[60] Song HB, Baranek A, Bowman CN. Kinetics of bulk photo-initiated copper(I)-catalyzed azidealkyne cycloaddition (CuAAC) polymerizations. Polym Chem 2016;7:603-12. doi:10.1039/C5PY01655J.

[61] Baranek A, Song HB, McBride M, Finnegan P, Bowman CN. Thermomechanical FormationStructure-Property Relationships in Photopolymerized Copper-Catalyzed Azide-Alkyne (CuAAC) Networks. Macromolecules 2016:10.1021/acs.macromol.6b00137. doi:10.1021/acs.macromol.6b00137.

[62] Bräse S, Gil C, Knepper K, Zimmermann V. Organic azides: An exploding diversity of a unique class of compounds. Angew Chemie - Int Ed 2005;44:5188-240. doi:10.1002/anie.200400657.

[63] Lu H, Stansbury JW, Dickens SH, Eichmiller FC, Bowman CN. Probing the origins and control of shrinkage stress in dental resin-composites: I. Shrinkage stress characterization technique. J Mater Sci Mater Med 2004;15:1097-103. doi:10.1023/B:JMSM.0000046391.07274.e6.

[64] Lu H, Stansbury JW, Dickens SH, Eichmiller FC, Bowman CN. Probing the origins and control of shrinkage stress in dental resin composites. II. Novel method of simultaneous measurement of polymerization shrinkage stress and conversion. J Biomed Mater Res Part B Appl Biomater 2004;71:206-13. doi:10.1002/jbm.b.30088.

[65] de Gee AF, Feilzer AJ, Davidson CL. True linear polymerization shrinkage of unfilled resins and composites determined with a linometer. Dent Mater 1993;9:11-4. doi:10.1016/01095641(93)90097-A.

[66] Patel MP, Braden M, Davy KWM. Polymerization shrinkage of methacrylate esters. Biomaterials 1987;8:53-6. doi:10.1016/0142-9612(87)90030-5. 
[67] Odian G. Principles of Polymerization. 4th ed. Wiley-Interscience: New York; 2004. doi:10.1002/047147875X.

[68] Cook WD, Brockhurst P. The Oscillating Rheometer - What Does It Measure? J Dent Res 1980;59:795-9.

[69] Rodrigues Junior SA, Zanchi CH, Carvalho RV de, Demarco FF. Flexural strength and modulus of elasticity of different types of resin-based composites. Braz Oral Res 2007;21:16-21. doi:10.1590/S1806-83242007000100003. 
Table 1. FTIR and DMA were used to measure functional group conversion, storage modulus at $40{ }^{\circ} \mathrm{C}$ $\left(\mathrm{E}^{\prime}{ }_{40^{\circ} \mathrm{C}}\right)$, and glass transition temperature $\left(\mathrm{T}_{\mathrm{g}}\right)$. Bulk photo-CuAAC polymer denoted as $\mathrm{BZ}-\mathrm{AZ}$ and BPA-AZ and dimethacrylate-based polymer denoted as BisGMA/TEGDMA were compared. Within each row, the letters indicate statistically significant differences $(\mathrm{p}<0.05)$ via a one-way ANOVA and a Tukey's test.

\begin{tabular}{l|l|l|l|l} 
& & BisGMA/TEGDMA & BZ-AZ & BPA-AZ \\
\hline $1^{\text {st }}$ cycle & Conversion [\%] & $74 \pm 2^{\mathrm{B}}$ & $99 \pm 1^{\mathrm{A}}$ & $78 \pm 9^{\mathrm{B}}$ \\
\cline { 2 - 5 } & $\mathrm{E}^{\prime} @ 40 \mathrm{C}[\mathrm{GPa}]$ & $2.2 \pm 0.2^{\mathrm{A}}$ & $2.0 \pm 0.1^{\mathrm{A}}$ & $2.3 \pm 0.2^{\mathrm{A}}$ \\
\cline { 2 - 5 } & $\mathrm{T}_{\mathrm{g}}[\mathrm{C}]$ & $67 \pm 6^{\mathrm{C}}, 154 \pm 2^{\mathrm{A}}$ & $63 \pm 1^{\mathrm{C}}$ & $84 \pm 2^{\mathrm{B}}$ \\
\hline $2^{\text {nd }}$ cycle & $\mathrm{E}^{\prime} @ 40 \mathrm{C}[\mathrm{GPa}]$ & $2.4 \pm 0.1^{\mathrm{A}}$ & $2.1 \pm 0.2^{\mathrm{B}}$ & $2.0 \pm 0.04^{\mathrm{B}}$ \\
\cline { 2 - 5 } & $\mathrm{T}_{\mathrm{g}}\left[{ }^{\circ} \mathrm{C}\right]$ & $153 \pm 1^{\mathrm{A}}$ & $64 \pm 1^{\mathrm{C}}$ & $105 \pm 1^{\mathrm{B}}$ \\
& & & &
\end{tabular}

Table 2. FTIR, tensometery, and linometery were used to measure functional group conversion, final polymerization shrinkage stress, and dynamic volumetric shrinkage, respectively. Bulk photo-CuAAC polymers denoted as BZ-AZ and BPA-AZ and a dimethacrylate-based control denoted as BisGMA/TEGDMA were compared. Each mixture was irradiated for $90 \mathrm{~s}$ at ambient temperature with $500 \mathrm{~mW} \mathrm{~cm}^{-2}$ of 400-500nm light. The only exception was made for BPA-AZ which was irradiated for $60 \mathrm{~s}$ in the volumetric shrinkage measurements. Conversion from shrinkage stress measurement is presented with conversion from volumetric shrinkage measurement being in parentheses. Within each row, the letters indicate statistically significant differences $(\mathrm{p}<0.05)$ via a one-way ANOVA and a Tukey's test. 


\begin{tabular}{l|l|l|l} 
& BisGMA/TEGDMA & BZ-AZ & BPA-AZ \\
\hline Conversion [\%] & $75 \pm 4^{\mathrm{B}}(77 \pm 3)^{\mathrm{C}}$ & $98 \pm 0.4^{\mathrm{A}}(98 \pm 1)^{\mathrm{A}}$ & $83 \pm 4^{\mathrm{B}}(87 \pm 0.2)^{\mathrm{B}}$ \\
\hline Shrinkage stress [MPa] & $1.3 \pm 0.08^{\mathrm{A}}$ & $0.43 \pm 0.07^{\mathrm{B}}$ & $0.27 \pm 0.03^{\mathrm{C}}$ \\
\hline Dynamic volumetric shrinkage [\%] & $7 \pm 0.08^{\mathrm{A}}$ & $6.2 \pm 0.3^{\mathrm{B}}$ & $6.4 \pm 0.6^{\mathrm{A}, \mathrm{B}}$ \\
\hline Shrinkage [ml/functionality] & $20 \pm 1^{\mathrm{A}}$ & $22 \pm 1^{\mathrm{A}}$ & $21 \pm 2^{\mathrm{A}}$
\end{tabular}

Table 3. A comparison of functional group conversions obtained after 4 min reaction time from FTIR $(X)$, flexural modulus $(E)$, flexural strength $(\sigma)$, flexural toughness $\left(G_{c}\right)$, and energy required to strain $11 \%\left(\mathrm{G}_{\mathrm{c}}{ }^{\prime}\right)$ measured from three-point bend test in Fig. 5 between bulk photo-CuAAC polymer denoted as BZ-AZ and dimethacrylate-based polymer denoted as BisGMA/TEGDMA. The letters indicate statistically significant differences $(\mathrm{p}<0.05)$ via a one-way ANOVA and a Tukey’s test.

\begin{tabular}{|c|c|c|c|c|c|c|c|}
\hline \multicolumn{4}{|c|}{ BisGMA/TEGDMA } & \multicolumn{4}{|l|}{ BZ-AZ } \\
\hline $\mathrm{X}[\%]$ & $\mathrm{E}[\mathrm{GPa}]$ & $\sigma[\mathrm{MPa}]$ & $\mathrm{G}_{\mathrm{c}}\left[\mathrm{MJ} \mathrm{m}^{-3}\right]$ & $\mathrm{X}[\%]$ & $\mathrm{E}[\mathrm{GPa}]$ & $\sigma[\mathrm{MPa}]$ & $\mathrm{G}_{\mathrm{c}}\left[\mathrm{MJ} \mathrm{m}^{-3}\right]$ \\
\hline $76 \pm 1^{\mathrm{B}}$ & $3.3 \pm 0.5^{\mathrm{A}}$ & $139 \pm 14^{\mathrm{A}}$ & $2.9 \pm 0.7^{\mathrm{B}}$ & $99 \pm 1^{\mathrm{A}}$ & $2.5 \pm 0.2^{\mathrm{A}}$ & $117 \pm 9^{\mathrm{B}}$ & $7.1 \pm 0.2^{\mathrm{A}}$ \\
\hline
\end{tabular}




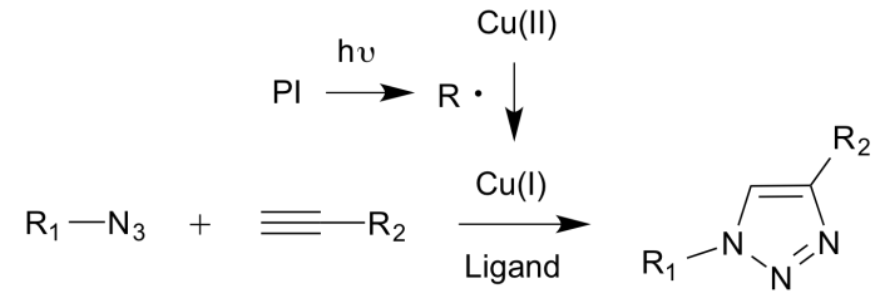

Scheme 1. A general reaction diagram for the photoinitiated CuAAC polymerization using a photoinitiator in three subsequent steps: photoinitiation, copper reduction to form $\mathrm{Cu}(\mathrm{I})$, and and $\mathrm{Cu}(\mathrm{I})$ catalyzed cycloaddition of azides and alkynes to form 1,2,3-triazoles.<smiles>C=C(C)C(=O)OCC(O)COc1ccc(C(C)(C)c2ccc(OCC(O)COC(=O)C(=C)C)cc2)cc1</smiles><smiles>CC(C)(NC(=O)OCCCCCCN)c1cccc(C(C)(C)NC(=O)OCCCCCCCN)c1</smiles><smiles>C=C(C)C(=O)OCCOCCOCCOC(=O)C(=C)C</smiles><smiles>CC12CCC(C(=O)C1=O)C2(C)C</smiles>

$C Q$<smiles>CCOC(=O)c1ccc(N(C)C)cc1</smiles>

EDAB

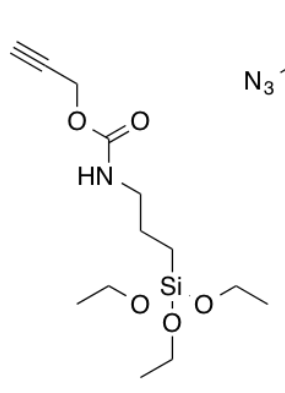

Si-AK

BZ-AZ<smiles></smiles>

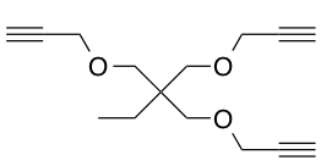

AK

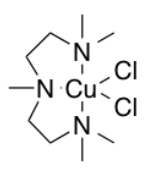

$\mathrm{CuCl}_{2}[\mathrm{PMDETA}]$

Figure 1. Monomer libraries of difunctional azides BZ-AZ, BPA-AZ, trifunctional alkynes AK, difunctional methacrylates BisGMA, TEGDMA, photoinitiator CQ, co-initiator EDAB, copper catalyst $\mathrm{CuCl}_{2}$ [PMDETA], alkyne silane Si-AK. 


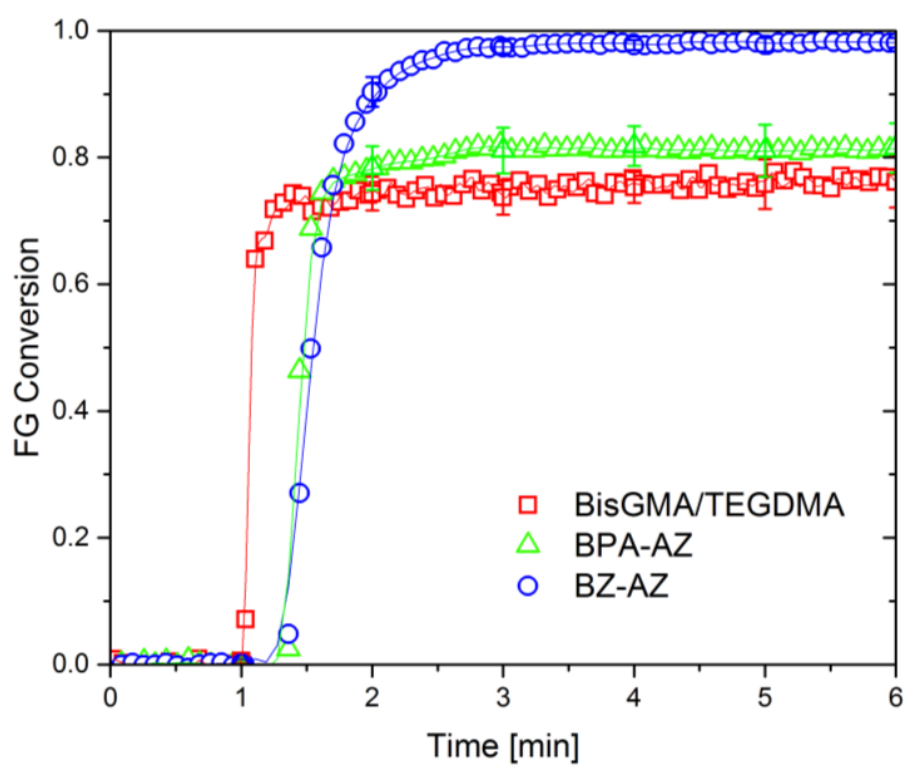

Figure 2. Polymerization kinetics of two bulk photo-CuAAC polymerizations labeled as BPA-AZ (green open triangle) and BZ-AZ (blue open circle) and BisGMA/TEGDMA polymerization as (red open square) as measured by FTIR $(n=3)$. Each mixture was irradiated for $90 \mathrm{~s}$ at ambient temperature with $500 \mathrm{~mW} \mathrm{~cm}^{-2}$ of $400-500 \mathrm{~nm}$ light following $1 \mathrm{~min}$ in the dark to establish a baseline.

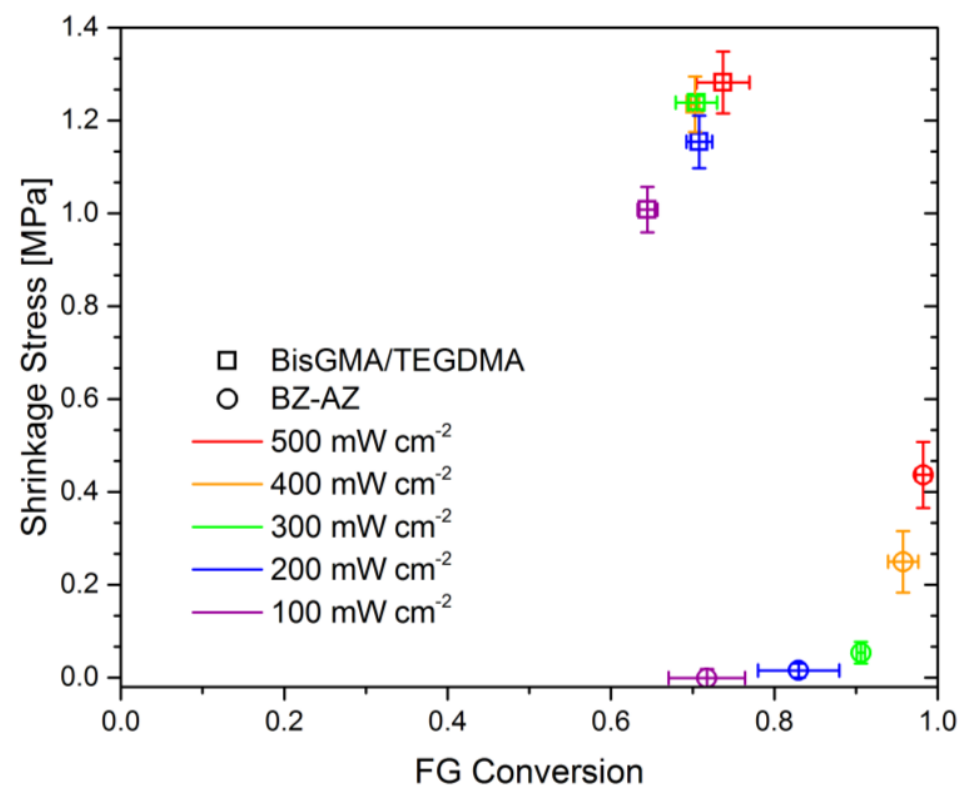

Figure 3. Polymerization shrinkage stress for bulk photo-CuAAC polymerizations labeled as BZ-AZ (open circle) and a BisGMA/TEGDMA control denoted as (open square) taken after 10 min of reaction 
time as a function of functional group conversion using a tensometer. Each mixture was irradiated for 90 $\mathrm{s}$ at ambient temperature with varying light intensities of 400-500nm light $-500 \mathrm{~mW} \mathrm{~cm}^{-2}$ (red), 400 $\mathrm{mW} \mathrm{cm}{ }^{-2}$ (orange), $300 \mathrm{~mW} \mathrm{~cm}^{-2}$ (green), $200 \mathrm{~mW} \mathrm{~cm}^{-2}$ (blue), $100 \mathrm{~mW} \mathrm{~cm}^{-2}$ (purple).

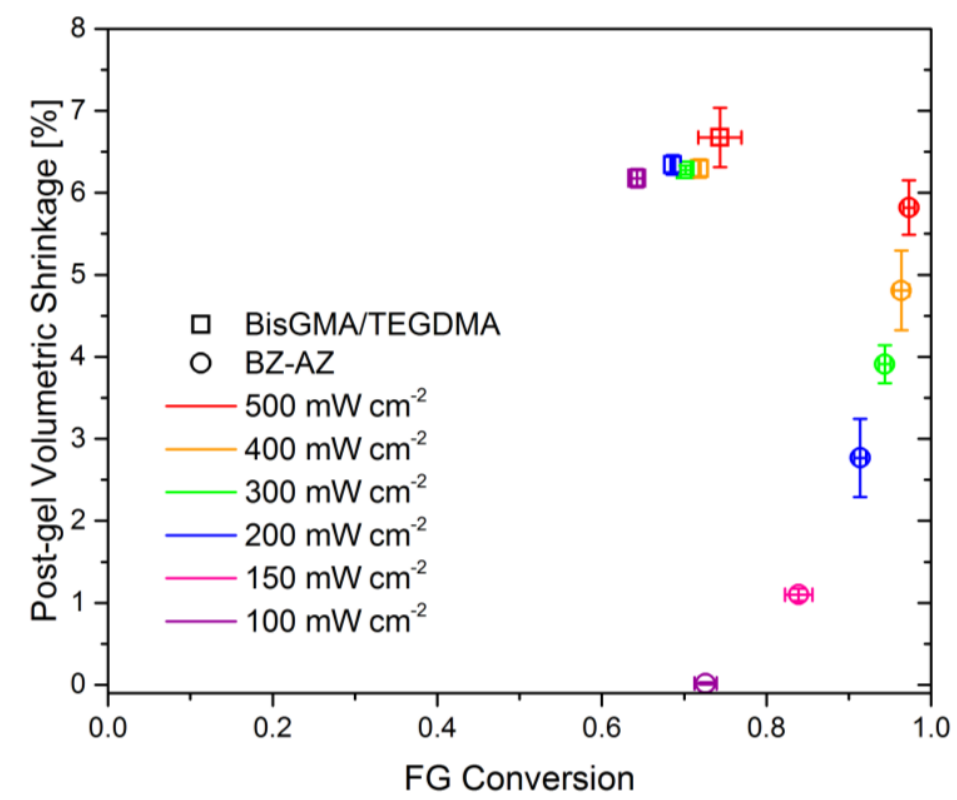

Figure 4. Average dynamic volumetric shrinkage of bulk photo-CuAAC polymerization denoted as BZAZ (open circle) and dimethacrylate polymerization denoted as BisGMA/TEGDMA (open square) taken following 5 minutes of reaction time as a function of functional group conversion. Each mixture was irradiated for $90 \mathrm{~s}$ at ambient temperature with different light intensities of 400-500nm light - 500 $\mathrm{mW} \mathrm{cm}$ (red), $400 \mathrm{~mW} \mathrm{~cm}{ }^{-2}$ (orange), $300 \mathrm{~mW} \mathrm{~cm}^{-2}$ (green), $200 \mathrm{~mW} \mathrm{~cm}^{-2}$ (blue), $100 \mathrm{~mW} \mathrm{~cm}^{-2}$ (purple). 


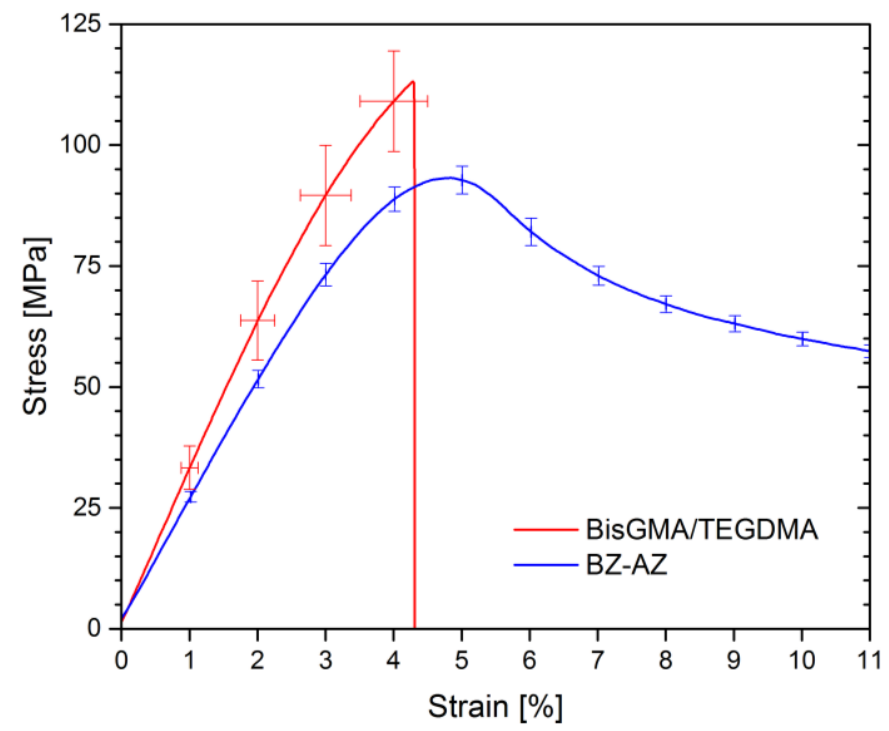

Figure 5. A representative stress-strain curve of bulk photo-CuAAC polymer denoted as BZ-AZ (blue solid line) and dimethacrylate-based polymer denoted as BisGMA/TEGDMA (red solid line) via threepoint bend in MTS. 
